\title{
Observed degradation in photovoltaic plants affected by hot-spots
}

\author{
Miguel García ，Luis Marroyo , Eduardo Lorenzo , Javier Marcos and Miguel Pérez
}

\begin{abstract}
A number of findings have shown that the test procedures currently available to determine the reliability and durability of photovoltaic (PV) modules are insufficient to detect certain problems. To improve these procedures, ongoing research into the actual performance of the modules in the field is required. However, scientific literature contains but few references to field studies of defective modules. This article studies two different localized heating phenomena affecting the PV modules of two large-scale PV plants in Spain. The first problem relates to weak solder joints whilst the second is due to microcracks on the module cells. For both cases, the cause is identified, and consideration is given with regard to the effect on performance, the potential deterioration over time, and a way to detect the problems identified. The findings contained in this paper will prove to be of considerable interest to maintenance personnel at large-scale PV plants and also to those responsible for setting module quality standards and specifications, and even the PV module manufacturers themselves.
\end{abstract}

\section{KEYWORDS}

hot-spots; hot cells; localized heating; reliability; quality control; commercial PV plants

\section{INTRODUCTION}

The term "hot-spot" is widely used to refer to any localized heating in the photovoltaic (PV) modules. This is the reason that lead the authors to use this term in the title. Nevertheless, it should be clarified that hot-spot normally describes an overheating caused by cell defects (junction breakdown). Therefore, is more correct to refer the problems described in this paper to as localized heating phenomena.

Localized heatings are the common symptom of many solar cell defects, such as shading, cracking, weak soldering, polarization, etc. Given the fact that thermographic cameras are now relatively inexpensive, thermal imaging has become a very common practice when analyzing the condition of PV arrays. Although theoretical analyses of localized heating phenomena are to be found in the literature from early PV times onwards [1-6], there is still a lack of widely accepted procedures for dealing with those problems in commercial applications [7]. Significantly, IEC 61215 [8], the most widely applied standard on PV module reliability, only considers hot-spot phenomena caused by partial shading, and whilst IEC 61646: 2009 [9] and some authors [10] mention the usefulness of thermal imaging analyses, no rules are provided for accepting or rejecting the modules affected. Not surprisingly, this failure to regulate this phenomenon can lead to controversies between buyers and sellers when localized heatings are detected in PV arrays. To a certain extent, this is due to the lack of a clear, empirically supported relationship between overheating magnitudes, such as temperature or number and their impact on PV generator performance in terms of efficiency and reliability.

This paper aims to help on that by providing consistent experimental observations on large-scale commercial PV plants affected by two different kinds of localized heating phenomena caused either by soldering defects or micro-cracks. 


\section{LOCALIZED HEATING CAUSED BY SOLDERING DEFECTS}

The PV plant under study has a maximum PV power output of $1.8 \mathrm{MWp}$ and comprises $3006 \mathrm{kWp}$ units, each mounted on a single axis azimuth tracker and coupled to the grid through a $5 \mathrm{~kW}$ inverter. Hereinafter, the group of modules associated with the same inverter shall be referred to as a "PV generator" or simply a "generator". Any anomaly affecting the energy production from these generators is easily detected simply by comparing the 300 values for monthly energy production given in the billing.

\subsection{Problem detection}

This PV plant has been in routine operation since 2006. During the first year of operation, no significant performance anomalies were detected. However, during the second year (2008), a slight drop in energy production was observed for a number of PV generators as a consequence of a decrease in their standard test condition (STC) power. The histograms for the generator STC power given in Figure 1 clearly show a drop from 2007 to 2010. To calculate the PV generator STC power, the current-voltage (I-V) curve of some of the generators was measured using an $\mathrm{I}-\mathrm{V}$ tracer (as described in [11]). These measurements served to calculate the STC power of the remaining generators, based on the methodology described in [12].

During the first year of operation, all the PV generators had an STC power of more than $90 \%$ of the nominal value. However, from 2008 onwards, a number of generators had power outputs of less than $90 \%$ of the nominal value. In 2009 , the drop in production (i.e., in the STC power output) for the aforementioned generators became more pronounced and other cases also appeared. At the same time, a significant number of blackened points in the TEDLAR were observed on these PV generators, clearly due to a localized heating phenomenon. The presence of those blackened points appeared to be directly related to this lower power output (Figure 2).

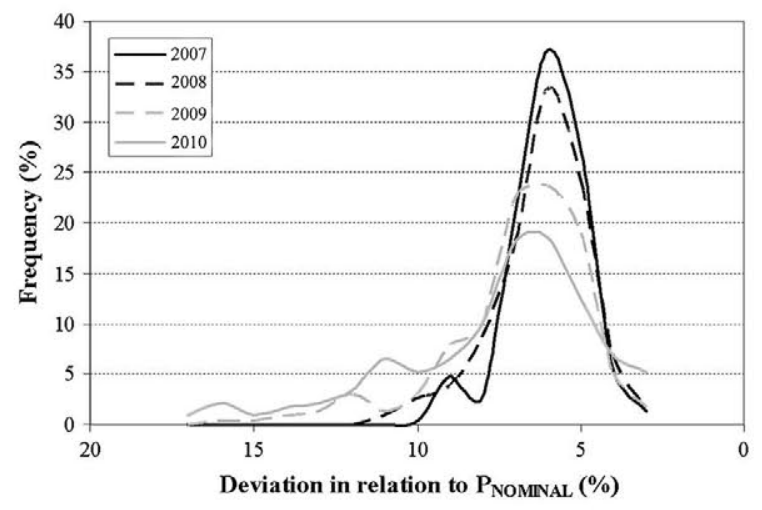

Figure 1. PV generator STC power histograms for the plant from 2007 to 2010. The STC power is expressed as a deviation from its nominal value.
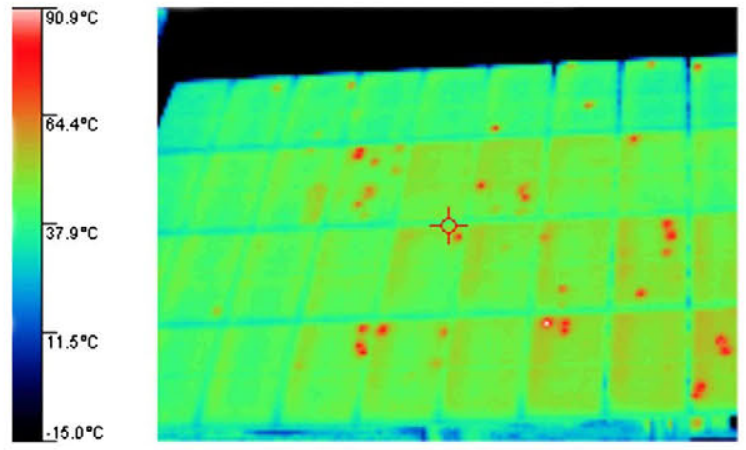

Figure 2. Thermal image of the defective generator, April 2009.

Contrary to former findings [6], the blackened points in this case were located over the two busbar tabs inside the cells (Figure 3). In some of these points, the TEDLAR backsheets were punctured, representing a risk of insulation failure (Figure 3.b).

Given the fact that the blackened points were randomly distributed on the affected generators, there is reason to think that there is no causal relation between the appearance of the localized heating phenomena and the PV generator shading.

During an initial visual inspection of the modules, it was only possible to detect those localized heatings that had actually damaged the TEDLAR backsheet. However, a subsequent inspection of the plant using a thermal imagining camera made it possible to establish that there were some localized heatings that had reached temperatures close to $150{ }^{\circ} \mathrm{C}$ and also that there were a large number of localized heatings that had not yet damaged the TEDLAR. Figure 4 shows one of those localized heating not visible to the naked eye.

It was also observed how some of the blackened points in the TEDLAR, were no longer hot, as shown in Figure 5. In such cases, the corresponding bypass diode was frequently conducting.

In 2010 , the problem grew to become more serious, with more than $17 \%$ of the generators with STC power outputs of below $90 \%$ of their nominal value. However, the module manufacturer, aware of the problem, replaced the affected modules. This explains the increase in the number of generators with an STC power output of over $95 \%$ of the nominal value in 2010, as shown in Figure 1.

Table I shows the mean value for the STC power deviations from the nominal value for the PV generators and the standard deviation for each year.

The aforementioned table shows how the mean plant STC power output remained approximately $6 \%$ below its nominal value during the first year (2007) and how this difference slowly increased with time. The generator power dispersion (i.e., the standard deviation) also showed a marked increase, particularly for 2009 and 2010.

\subsection{Cause of the phenomenon (lab tests)}

To determine the causes of the decreased power output of those generators with localized heatings, a series of tests 


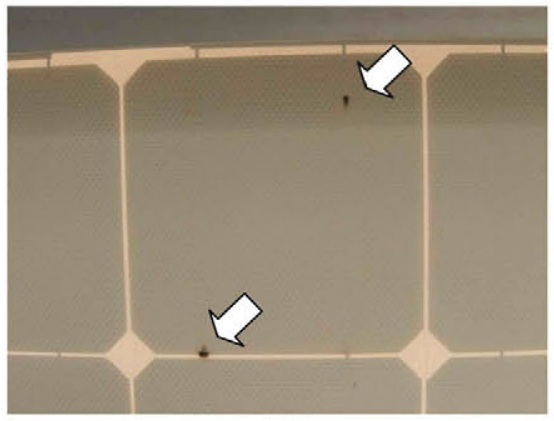

(a)

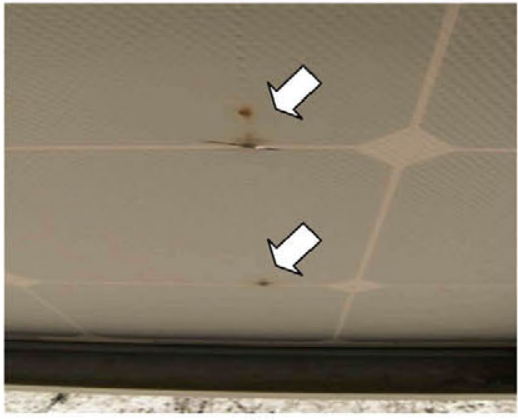

(b)

Figure 3. Localized heating effects on the modules of the PV plant. The overheating were produced on the two busbar tabs inside each cell: (a) Blackened points in the TEDLAR and (b) Punctured TEDLAR.

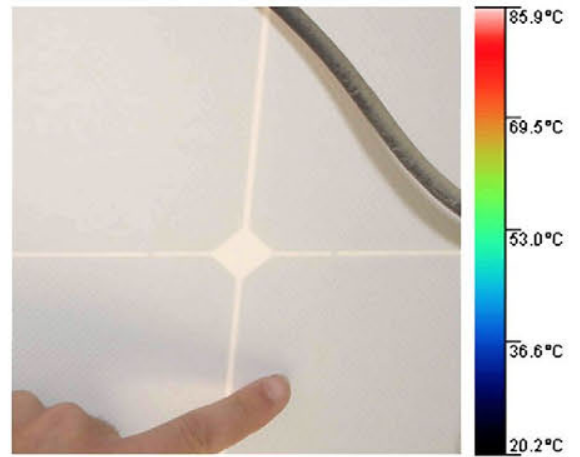

(a)

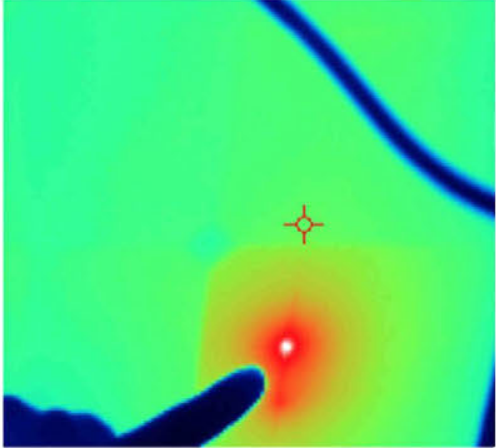

(b)

Figure 4. (a) Image of a module with a localized heating; (b) Thermal image of the module showing how it has a temperature over $85^{\circ} \mathrm{C}$. The presence of the overheating is not yet visible to the naked eye.

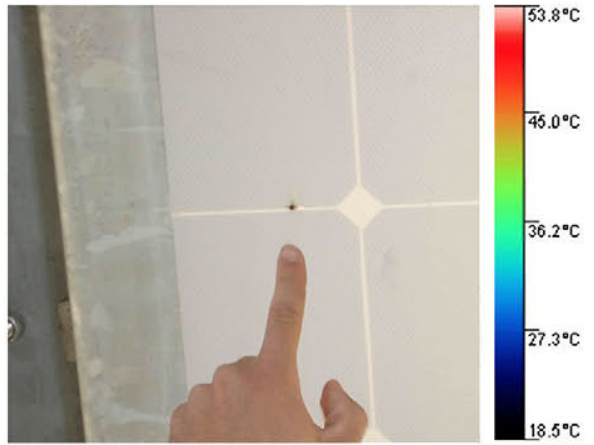

(a)

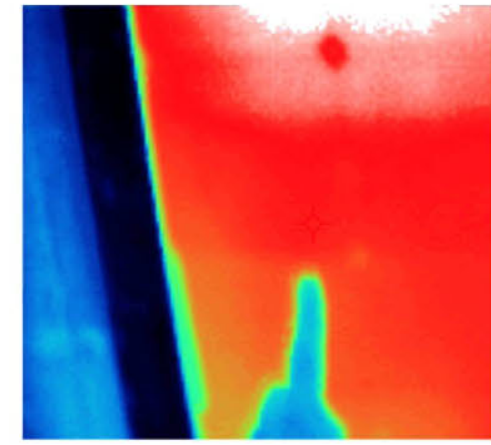

(b)

Figure 5. (a) Image of the blackened point in the TEDLAR of one of the modules caused by a localized heating. The heat had punctured the TEDLAR. (b) Thermal image of the module in which the overheating does not show up.

Table I. Mean value and standard deviation of the STC power difference from its nominal value from 2007 to 2010 .

\begin{tabular}{llllr}
\hline & 2007 & 2008 & 2009 & 2010 \\
\hline Mean (\%) & 6 & 6.2 & 6.9 & 7.6 \\
STD deviation (\%) & 1.25 & 1.61 & 2.22 & 3.1 \\
\hline
\end{tabular}

were run on the affected modules. Firstly, the I-V curve of some of the modules with blackened points was measured. The measurements were taken with capacitive load, whilst also measuring the radiation and cell temperature with a calibrated module [11]. Figure 6 shows the I-V curves for 4 of the 36 modules of a generator (Figure 6a) and power-voltage curve (Figure $6 \mathrm{~b}$ ) under standard test 


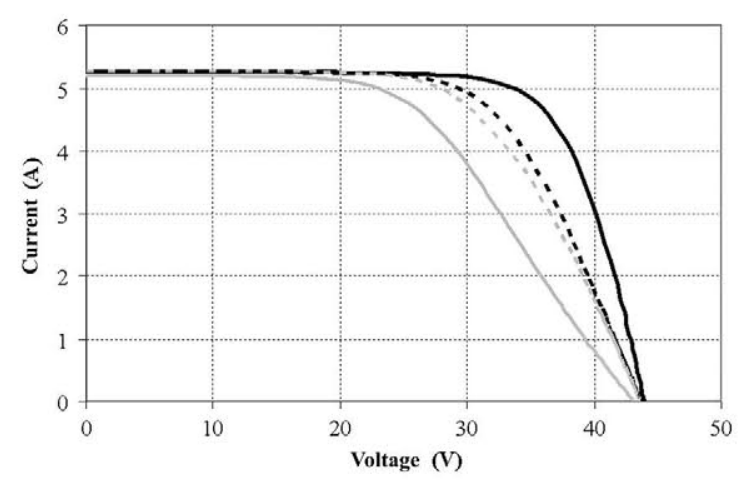

module 17 ( 0 blackened points) - - module 16 (1 blackened point) - module 18 (4 blackened points) _ - - module 8 ( 8 blackened points)

(a)

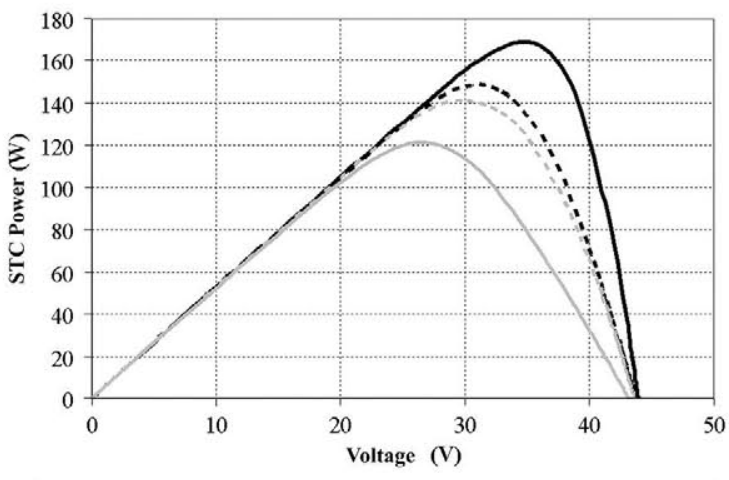

module 17 ( 0 blackened points $)$ - - module 16 (1 blackened point $)$ module 18 (4 blackened points) module 8 ( 8 blackened points)

(b)

Figure 6. (a) $I-V$ curve and (b) P-V curves, in STC for four modules of a generator severely affected by localized heatings.

conditions (STC). There was no sign of localized heatings in one of the modules, whereas it was possible to observe 1, 4 and 8 blackened points in the TEDLAR respectively, in the other three.
Figure 6 illustrates how the presence of those localized heatings has the same effect on the $\mathrm{I}-\mathrm{V}$ curve as a resistor connected in series with the module. Furthermore, the impact of the localized heating is not only dependent on quantity but also on the state of degradation and on whether the localized heatings are on the same block or on different blocks. For instance, although module 18 shows fewer blackend points in the TEDLAR than module 8 , it actually has a greater effect on the pressure-volume curve.

As a simple test to check the condition of the soldering in those cells affected by localized heatings, the busbar tabs were pulled out (once the TEDLAR and EVA layers had been removed). Figure 7 shows the analysis of the imprint left by the tabs: the only electrical contact between the tabs and the metal surface covering the back of the cells occurred at the solder joints. In these modules, there were four solder joints per tab. For the remaining points, the space between the tab and the conducting surface were filled by an encapsulant (electrical insulator). The solder joints for one of the two tabs pulled off (the upper tab) had a very small surface area, indicating a weak weld.

Interestingly, the overheating did not appear on the weakest solder joints but on those tabs that were better soldered (lower tab on Figure 7). To explain this fact, it should be borne in mind that the two collecting tabs are the only path for the current generated by the cell. If both tab solderings have the same electrical resistance, then the current will be divided equally between them. However, if one of these tabs has an abnormally high electrical resistance, then the current would tend to flow through the path with the lowest electrical resistance. The resistance of defective solder joints may be high enough to force almost all the current to pass through the strongest solder joints. This concentration of the current in small areas is responsible for the temperature increase in these areas and is therefore the cause of the hot-spots observed. This cause is different from the one found in other plants also experiencing soldering problems [6].

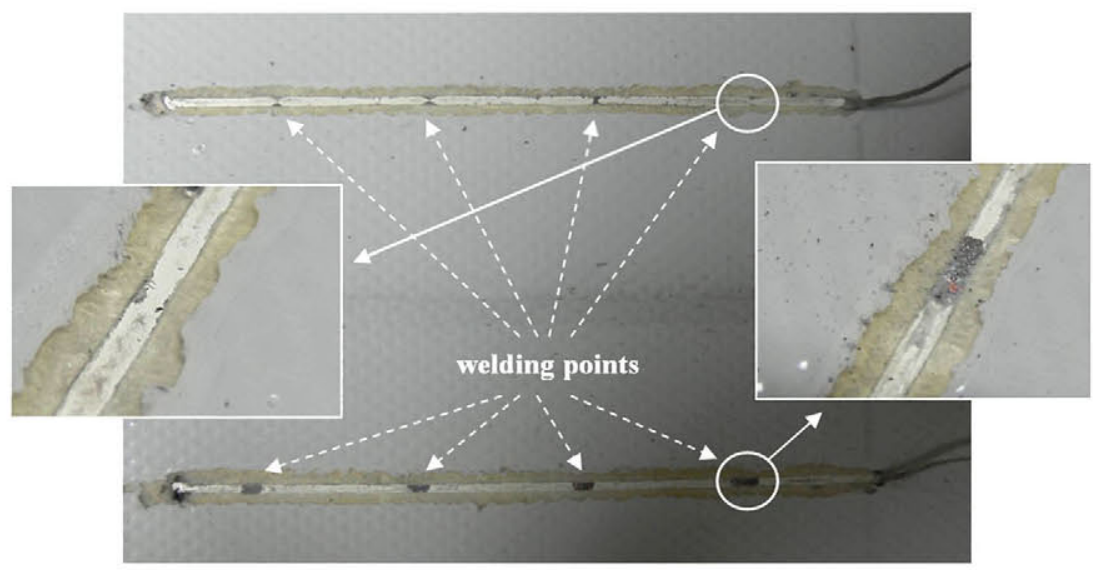

Figure 7. Imprints left by the busbar tab on the back of the cells after being pulled off by hand. 
Weak solder joints were observed not only on cells affected by localized heating phenomena but also on cells that were apparently sound and even on cells of modules that had never been exposed to solar radiation. All the modules affected by localized heating phenomena were seen to have been manufactured between August and September 2004, whilst the least affected modules had been manufactured in some other month. This all suggests that the root cause was a manufacturing problem basically occurring during those 2 months.

\subsection{Effects on the power output}

At the end of 2009, a thorough inspection was made of all the PV generators in the most affected areas of the plant, quantifying the number of modules with blackened points in the TEDLAR. Figure 8 shows the STC power output for those generators in relation to the number of modules with blackened points in the TEDLAR.

The linear fitting of the points gave the following relation: $P^{* /} P_{\text {NOMINAL }}=0.940 .00047 \cdot N_{\mathrm{H}-\mathrm{S}}$, where $N_{\mathrm{H}-\mathrm{S}}$ is the number of modules with blackened points per generator. The slope of the line indicates that the average decrease of the generator power output is $0.47 \%$ for each module with blackened points in the TEDLAR. Each PV generator comprises 216 blocks, where a "block" is a module sub-string of cells associated with a single bypass diode. Therefore, one of these blocks accounts for $0.46 \%$ of the entire generator, which approximately corresponds to the decrease in the PV generator mean power output per module with blackened points. It could therefore be concluded that, in the majority of cases, the presence of localized heatings tends to force the bypass diode to conduct, due to the total loss of electrical contact in the affected cell (s), as verified in the thermographic inspection.

\subsection{Degradation over time}

As mentioned at the start of this paper, the STC power output decreased as the number of affected generators markedly increased each year. The decrease in the generator power output over time could be explained by the fact that

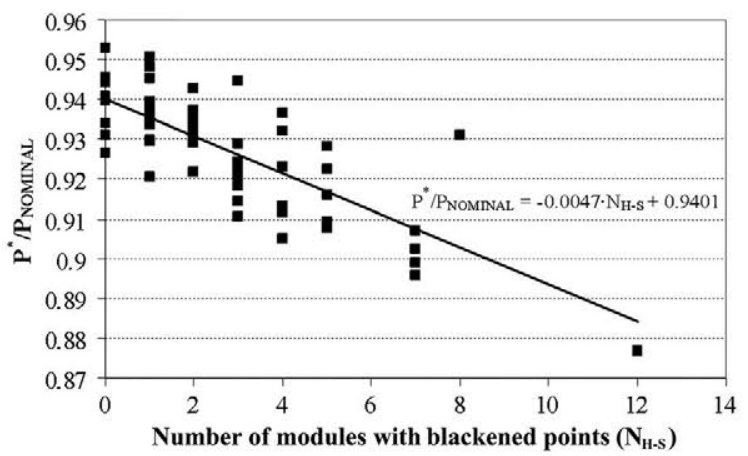

Figure 8. STC power output of the generators from the most severely affected areas of the plant, in relation to the number of modules with blackened points in the TEDLAR. laboratory inspections revealed weak solder joints in apparently sound modules and even in modules that had never been exposed to solar radiation. The probability of such modules developing localized heatings is fairly high, and this appears to have been the case for those modules installed at the plant and which initially showed no signs of localized heating problems. In fact, the presence of localized heatings not visible to the naked eye in the thermal images taken in mid 2010 (4 years after the plant commissioning) suggest that the deterioration process had still not stabilized at that time. Up till then, the number of modules affected amounted to 1545 , accounting for $13 \%$ of the total number of modules installed. Indeed, the following year, new blackened points appeared and the power output of the generators affected continued to fall. However, the mass replacement of the defective modules by the manufacturer from that year onwards made it impossible to continue the degradation study.

\section{LOCALIZED HEATING CAUSED BY MICRO-CRACKS}

Solar cell micro-cracks are a well-known problem in the PV sector [13-18]. Today, it is not easy to quantify their influence on the efficiency of PV modules and generators over their service life. Although a number of laboratory studies have been made [16-18], the available literature contains no consistent experimental data relating to the occurrence of this type of problem in commercial plants. Although it is possible to clearly identify micro-cracks through electroluminescence, the use of thermal imaging is, in many cases, a simpler and cheaper method, and, as discussed in this paper, it could be effective in detecting problems of this type when the cracks leave part of the cell completely isolated. As shown in earlier studies [18], these particular cracks are precisely those that cause significant power losses in PV modules. In fact, over the last few years, the systematic thermal imaging of the PV generators has become common practice, and at some plants, this has revealed cells with a significantly higher temperature than the other cells. These hot cells might be a sign of a number of problems, including micro-cracks.

We shall now go on to discuss the specific case of a PV plant with a peak power of more than $3.8 \mathrm{MW}$, comprising more than $550,6.8 \mathrm{KWp}$ generators mounted on a single azimuth axis. Each generator delivers power to the grid through a $5 \mathrm{~kW}$ inverter. As in the case of the aforementioned PV plant, any anomaly affecting energy production is easily identified simply by comparing the more than 550 values of monthly energy production in the billing.

\subsection{Identification of the problem}

The plant was commissioned in 2007. A thermal imaging inspection carried out in 2010 showed a large number of cells with temperatures that were considerably higher than the rest 


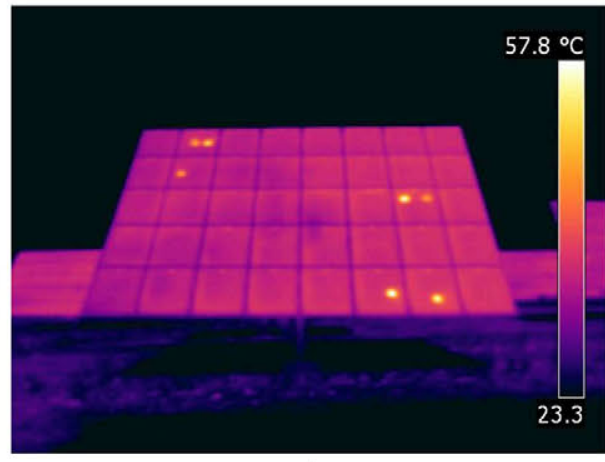

a)

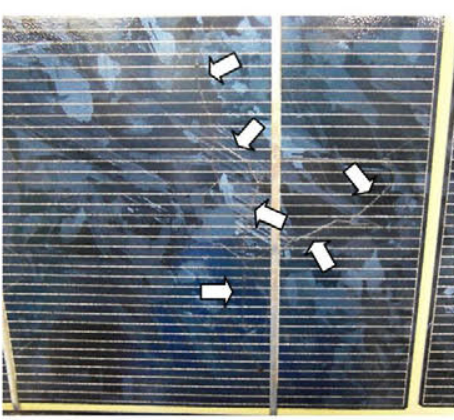

b)

Figure 9. (a) Thermal image of a PV generator with five modules affected by hot cells and (b) Image of one of the hot cells (cracked cells).

(around $15^{\circ} \mathrm{C}$ higher, with approximately $1000 \mathrm{~W} / \mathrm{m}^{2}$ irradiance), as shown in Figure 9.

The effect of this phenomenon on the PV generator production appeared to be negligible. Figure 10 shows the

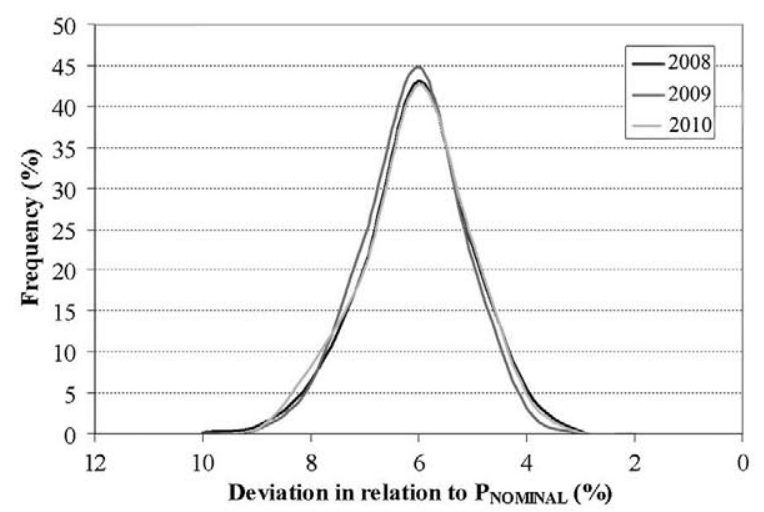

Figure 10. Histogram of the STC power for the PV generators from 2008 to 2010. The STC power is expressed at a deviation in relation to the nominal value (as a \%). histogram of the generator STC power from 2008 to 2010. The power was calculated in the same way as for the PV plant described earlier [12]. As the power outputs approximately fitted a normal distribution, there did not appear to be any trackers with an unusually low power output

Given the fact that a thorough inspection revealed the presence of micro-cracks in a large number of hot cells (Figure 11b), it was decided to study the problem in greater detail.

\subsection{Nature of the phenomenon (lab tests)}

The effects of the cracked cells on the PV module electrical performance are only evident when the cracks lead to isolated cell areas [18]. Figure 12a and b show the I-V curves for two of the defective modules (red). In this case, the modules comprise three blocks. The dashed lines in Figure 12 correspond to the imaginary lines obtained by dividing the modules into blocks. Both modules had two sound blocks and one block with hot cells. Alongside these curves, the I-V curve (blue) of a sound module has also been plotted.

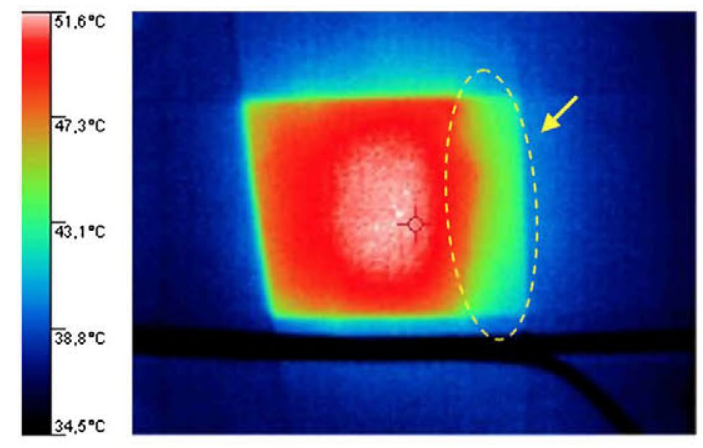

(a)
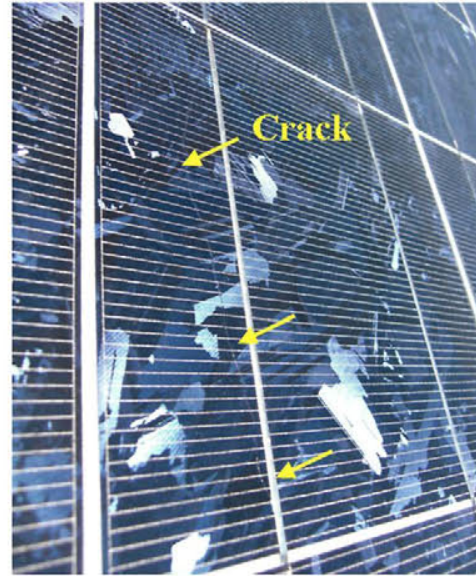

(b)

Figure 11. (a) Thermal image and (b) Image of the front side of a cracked cell. 


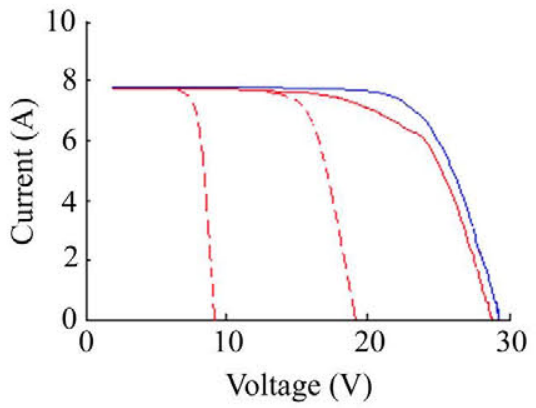

(a)

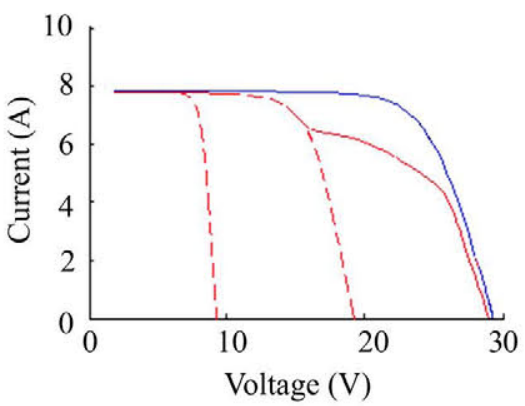

(b)

Figure 12. I-V curves of two modules with hot cells (red) and the curve of a sound module (blue).

Modules with hot cells, as plotted in Figure 12, show I-V curves similar to those of partially shaded modules. Several of the thermal images showed many hot cells to have some areas that were noticeably colder, corresponding to areas that were completely isolated from the rest of the cell. Depending on the size of the isolated area, the curve step (i.e. the severity of the defect) would be either larger or smaller, explaining the differences between Figure $12 \mathrm{a}$ and $\mathrm{b}$.

\subsection{Effects on production output (experimental and theoretical approach)}

Although in principle, the impact of the hot cells on the STC power of the generators appeared not to be significant, thermal images of all the generators were taken, and the number of hot cells per generator was counted. To determine whether or not there was any correlation between the number of hot cells per generator and the STC power output, it was decided to electrically consider each generator as a set of blocks connected in series and in parallel (that is each of the modules comprised three blocks). Figure 13 shows the STC power for each generator against the number of blocks with hot cells.

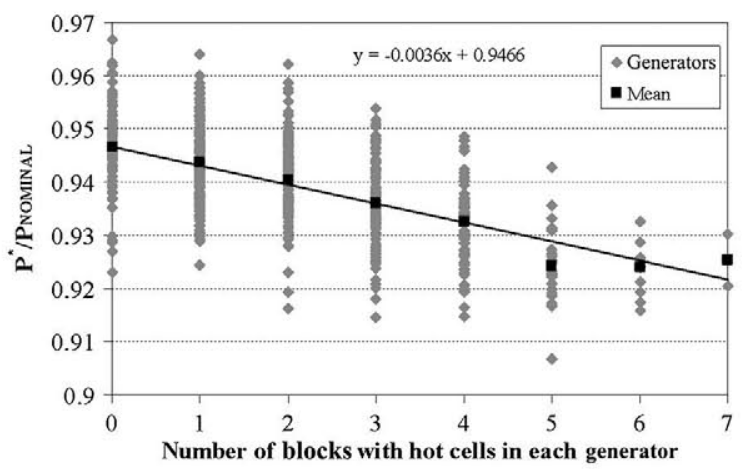

Figure 13. Generator STC power (related to the nominal value) versus number of blocks with hot cells. The black dots mark the mean power of generators with the same number of blocks with hot cells. The black line shows their linear fitting.
There is an evident correlation between the generator STC power and the number of blocks with hot cells. Each block with hot cells represents a mean decrease in generator power of $0.36 \%$.

In an attempt to find the theory behind the observed correlation between hot cells and the power output of the generators affected, it was decided to simulate the effect of introducing a defective module with hot cells into a sound generator. Two cases were considered: the first assumed that the I-V curve of the defective module was as shown in Figure 12a (corresponding to a "slight" defect), whilst the second case considered the curve shown in Figure 12b (corresponding to a "major" defect). Figure 14 shows the I-V curves for the modules for both simulated cases, together with their maximum power points (MPP) and their actual operating points, assuming that the operating point of the whole generator is the global MPP. The PV modules were divided into three groups: defective module, modules connected in series with the defective one, and the remaining modules.

The maximum power point of a photovoltaic generator (in other words, its operating point) corresponds to a voltage at which most modules in the generator are operating close to their respective MPP. Thus, the mismatch losses are minimal. However, when a PV module shows an abnormal $\mathrm{I}-\mathrm{V}$ curve (defective module), then the operating voltage of this module remains below its maximum power voltage whilst the voltage of the modules connected in series with it remain slightly above the voltage of their MPP (as shown in Figure 14). Therefore, the generator power losses are the result of three factors: the slightly lower power of the defective module (caused by the defect itself); the deviation of this module from its maximum power point; and the mismatch losses that the defective module causes on the rest of the generator modules, mainly on those modules connected in series with it. Thus, it is worth noting that the total power loss caused by a defective module in a PV generator is greater than the actual decrease in the maximum power experienced by this module considered separately.

Furthermore, observation revealed that the hot cells operate in reverse polarity mode (dissipating energy). For this reason, their temperature is above the rest. Nevertheless, in 


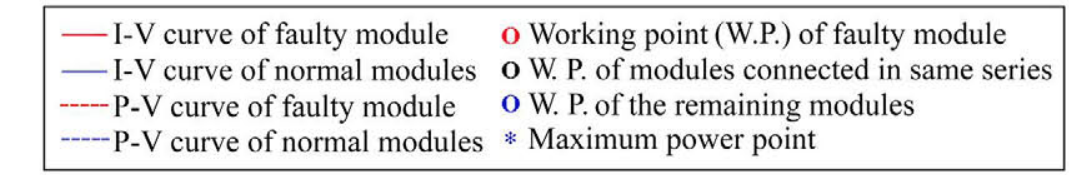

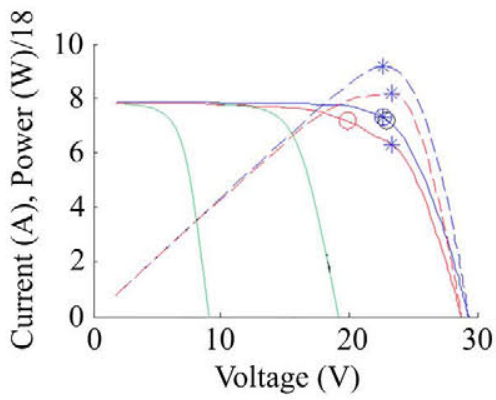

(a)

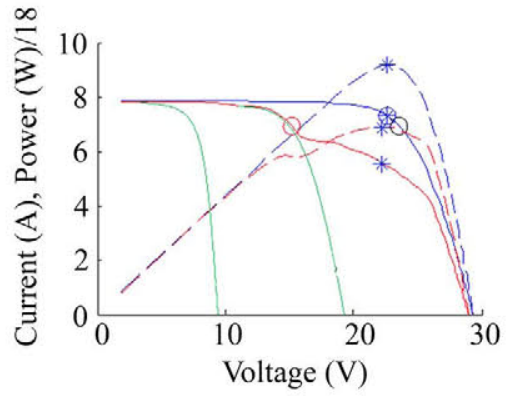

(b)

Figure 14. V-I curves, maximum power point and operating point for the PV modules making up the simulated generator: (a) Module with a slight defect and (b) Module with a major defect.

the case shown in Figure 14b, the defect in the faulty module forces the corresponding bypass diode to conduct, whereas the defect in the faulty module of Figure 14a is not severe enough to force the bypass diode to do so. Such behavior was experimentally verified, as shown in Figure 15. It is easy to understand that the maximum power loss caused by a cracked cell corresponds to the power of a whole block (when the diode is forced to conduct) plus the mismatch losses caused to the rest of the blocks. It is thus of interest to determine how often a cracked cell causes the corresponding bypass diode to conduct.

The energy loss of an entire block, as the diode starts to conduct, is $0.83 \%$ (1/120 total number of blocks in a PV generator). Adding approximately $0.3 \%$ for mismatch losses in the remaining blocks, the total power loss is $1.2 \%$ per block with cracked cells. On the other hand, simulation results (Figure 16) revealed that a defective block, with a slight defect (similar to that shown in Figure 12a) approximately involves a mean energy loss of $0.3 \%$. However, the field measurements shown in Figure 14 suggest that each defective block has an average effect on the power loss of $0.36 \%$. This value is much closer to the loss

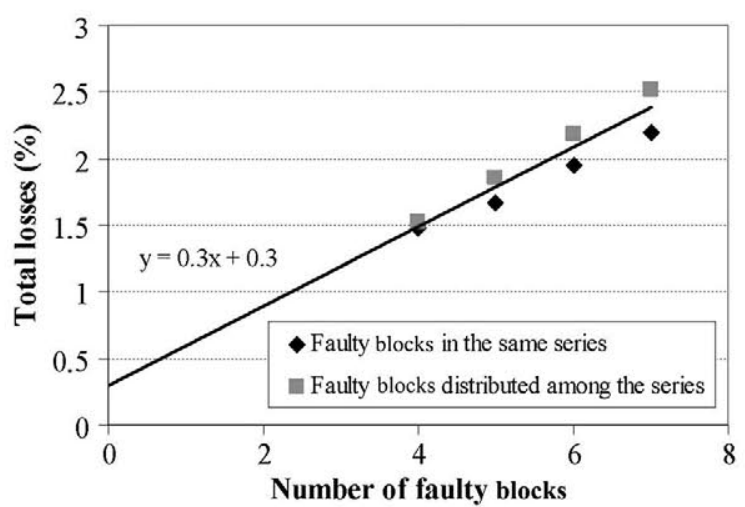

Figure 16. Total energy losses in a PV generator in relation to the number and position of the faulty blocks.

caused by a slight defect $(0.3 \%)$ than the power loss produced when a bypass diode conducts $(1.2 \%)$. Therefore, it seems likely that in most cases, the bypass diodes do not conduct.

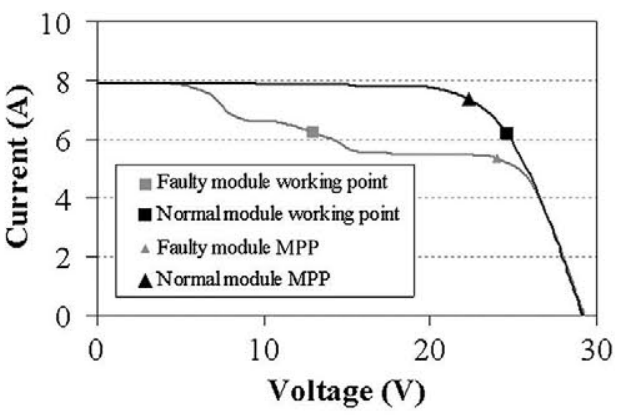

(a)

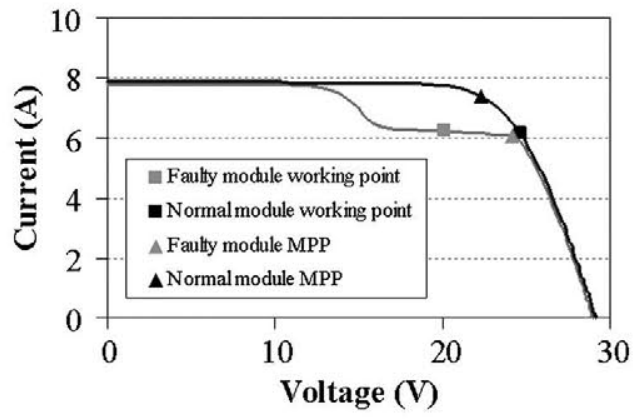

(b)

Figure 15. I-V curves and operating points measured in the field: (a) sound module and module with two blocks affected by hot cells and (b) sound module and module with one block affected by hot cells. The maximum power points are also indicated for each curve. 


\subsection{Degradation over time}

The power histogram in Figure 10 shows that there is little variation in the generator STC power over the 3 years studied. This appears to indicate that the hot cell phenomenon stabilized during the first year of plant operation. Based on the thermal imaging inspection carried out in 2010, amongst other things, it was possible to determine that the total number of modules affected was $1259 ; 5.7 \%$ of the total number of modules installed. No new hot cells were detected over the following year, confirming the fact that there was no discernible degradation over time. However, as in the case of the other plant, it was not possible to continue the degradation study once the manufacturer had replaced the defective modules.

Therefore, the problem appears to be less important than the problem of weak solder joints described in the previous section, not only because there is a smaller percentage of affected modules but also because there is no longer degradation over time. Also, unlike the soldering case, in most cases, the bypass diodes do not conduct. Therefore, if the PV generators were equal in both plants studied, then the average power loss per defective block would have been lower in the case of the plant with cracked cells.

\section{CONCLUSIONS}

This paper has discussed the formation of localized heatings due to weak soldering in the two busbar tabs inside the cells, causing a high contact resistance, which increases with time due to thermal stresses. As a result, the current tends to concentrate in the rest of the solder joints (offering lower resistance), raising their current density. Consequently, the temperature increases at these points (localized heatings). Sufficient heat may even be generated to cause the encapsulant (EVA) to deteriorate. The effect of this phenomenon on the PV generator output depends on the number of blocks affected and the extent of solder joint deterioration. The progressive deterioration caused by thermal stress leads to a reduction in the generator power output over time. In most cases, deterioration causes the bypass diode to conduct, so that the generator power loss would end up being equal to the power loss of the affected blocks plus a small power loss due to deviation from the optimal operating setpoint for the rest of the blocks (mismatch losses). If these localized heatings damage the TEDLAR layer (blackening), then they are detectable at sight, otherwise they are only detectable through thermal imaging. It is extremely hard to detect this problem simply by observing the $\mathrm{I}-\mathrm{V}$ curves for the generator as a whole, and it cannot be detected by measuring the generator open circuit voltage. This is a serious problem, considering the number of modules that could be affected if the manufacturer is unaware of the problem, due to the subsequent power output loss in the modules. Furthermore, this problem worsens over time.
The second problem relates to hot cells caused by microcracks. In this case, the affected cells have an electrically isolated area, which is unable to deliver power to the circuit (the cell short-circuit current decreases). This unproductive cracked area is thus similar to a shaded area, with the same effects. One of these effects is the overheating of the cell due to reverse polarity. The temperatures reached are not as high as the temperatures caused by a soldering defect (a $10-20^{\circ} \mathrm{C}$ increase above the average temperature of the module, depending on ambient conditions); however, the temperatures are high enough to allow the problem to be detected through thermal imaging. If the micro-cracks did not electrically isolate an area of the cells, then thermal imaging would not reveal the presence of a crack. However, in this latter case, the effect of the micro-cracks on production would be negligible.

The maximum theoretical loss per defective block corresponds to a case in which the corresponding bypass diode conducts. As in the former case, this would be equal to the loss of power corresponding to that block, plus the mismatch losses caused on other blocks, mainly those of the same series. However, unlike the first case, the bypass diode is less likely to conduct; hence, the losses would be lower.

On the other hand, once the cell has cracked (during the manufacturing process, in storage, during transportation, etc.) and part of the cell has become completely isolated, then the phenomenon does not appear to worsen over time. Furthermore, the temperatures reached tend to be lower than in the first case and in most scenarios, the heat does not damage the TEDLAR and, therefore, the module integrity is rarely at risk, at least in the short term, although this condition could lead to premature aging.

\section{FURTHER THOUGHTS}

Based on the findings set out in this paper, there is a need to reflect on some points showing that the present-day PV plant quality assurance standards and procedures are not enough to contemplate the extent of the problems discussed herein. At present, these procedures merely require the modules to be certified to IEC 61215 or similar and to impose tolerances for their power values measured by using solar simulators. This could have implications on agreements reached between buyers and sellers with regard to PV module supply contracts:

- Both problems discussed herein could possibly appear several years after the plant commissioning, even after initial compliance with the normal quality controls for the modules. Those localized heatings puncturing the TEDLAR are visible, and therefore constitute a visual inspection failure according to IEC 61215. However, those localized heatings that have not yet damaged the TEDLAR (either due to soldering defects or to cracked cells), are only visible through thermal imaging (or electroluminescence). Hence, the latter situation should be contemplated in purchase agreements and warranties. 
- The effects of these problems may be destructive in the short term or otherwise shorten the service life in the long term.

- The energy losses of the defective modules are not only related to a reduction in maximum power due to anomalies with the $\mathrm{I}-\mathrm{V}$ curve. When a defective module is coupled to other modules, such anomalies cause the operating voltage to be much lower than the maximum power point voltage (and may even force the remaining modules to operate outside their maximum power points). The total associated power loss would thus be higher than that of the module considered separately. Therefore, it is not sufficient to impose tolerance conditions on the maximum power values of the modules.

\section{REFERENCES}

1. Blake FA, Hanson KL. The hot-spot failure mode for solar arrays. Proceedings of the $4^{\text {th }}$ Intersociety Energy Conversion Engineering Conference, 1969: 575-581.

2. Herrmann W, Wiesner W, Vaasen W. Hot-spot investigations on PV modules-new concepts for a test standard and consequences for module design with respect to by-pass diodes. Proceedings of the $26^{\text {th }}$ Photovoltaic Specialists Conference, Anaheim 1997; 1129-1132.

3. Molenbroek E, Waddington DW, Emery KA. Hot-spot susceptibility and testing of PV modules. Proceedings of the $22^{\text {nd }}$ IEEE Photovoltaic Specialists Conference, Anaheim 1991; 547-552.

4. Wohlgemuth JH, Conway M, Meakin DH. Reliability and performance testing of photovoltaic modules. Proceedings of the $28^{\text {th }}$ IEEE Photovoltaic Specialists Conference, Anaheim 2000; 1483-1486.

5. Alonso-García MC, Herrmann W, Böhmer W, Proisy B. Thermal and electrical effects caused by outdoor Hot-spot testing in associations of photovoltaic cells. Progress in Photovoltaics: Research and Applications 2003; 11: 293-307. DOI:10.1002/pip.490

6. Muñoz J, Lorenzo E, Martínez-Moreno F, Marroyo L, García M. An investigation into hot-spots in two large grid-connected PV plants. Progress in Photovoltaics: Research and Applications 2008; 16: 693-701. DOI:10.1002/pip.844

7. Osterwald C, McMahon T. History of accelerated and qualification testing of terrestrial photovoltaic modules: a literature review. Progress in Photovoltaics: Research and Applications 2009; 17: 11-33. DOI:10.1002/pip.861
8. IEC Standard 61215. Crystalline Silicon Terrestrial Photovoltaic (PV) Modules - Design Qualification and Type Approval. International Electrotechnical Commission, 1995.

9. IEC Standard 61646. Thin-film Terrestrial Photovoltaic (PV) Modules-Design Qualification and Type Approval. International Electrotechnical Commission, 2008.

10. Muñoz MA, Alonso-García MC, Vela N, Chenlo F. Early degradation of PV modules and guaranty conditions. Solar Energy 2011; 85: 2264-2274. DOI:10.1016/j.solener.2011.06.011

11. Martinez-Moreno F, Lorenzo E, Muñoz J, Moretón R. On the testing of large PV arrays. Progress in photovoltaics: Research and Applications 2012; 20 : 1. DOI: $10.1002 /$ pip. 1102

12. García M, Vera JA, Marroyo L, Lorenzo E, Pérez M Solar-tracking PV plants in Navarra: a 10MW assessment. Progress in photovoltaics: Research and Applications 2009; 17: 337-346, DOI: 10.1002/pip.893

13. Pingel S, Zemen Y, Frank O, Geipel T, Berghold J. Mechanical stability of solar cells within solar panels. Proceedings of the $24^{\text {th }}$ European Photovoltaic Solar Energy Conference, Dresden 2009; 3459-3464.

14. Grunaow P, Clemens P, Hoffmann V, Litzenburger B, Podlowski L. Influence of micro cracks in multicrystalline silicon solar cells on the reliability of PV modules. Proceedings of the $20^{\text {th }}$ European Photovoltaic Solar Energy Conference, Barcelona 2005; 6-10.

15. Gabor AM, Ralli M, Montminy S, Alegria L, Bordonaro C, Woods, J, Felton L. Soldering induced damage to thin Si solar cells and detection of cracked cells in modules. Proceedings of the $21^{\text {st }}$ European Photovoltaic Solar Energy Conference, Dresden 2006; 4 -8.

16. Kajari-Schröder S, Kunze I, Eitner U, Köntges M. Spatial and orientational distribution of cracks in crystalline photovoltaic modules generated by mechanical load tests. Solar Energy Materials and Solar Cells 2011; 95: 3054-3059.

17. Köntges M, Kajari-Schröder S, Kunze I, Jahn U. Crack statistic of crystalline silicon photovoltaic modules. Proceedings of the $26^{\text {th }}$ European Photovoltaic Solar Energy Conference, Hamburg 2011.

18. Köntges M, Kunze I, Kajari-Schröder S, Breitenmoser $\mathrm{X}$, Bjorneklett $\mathrm{B}$. The risk of power loss in crystalline silicon based photovoltaic modules due to microcracks. Solar Energy Materials and Solar Cells 2011; 95: 1131-1137. 